\title{
“TOLERÂNCIA ZERO PARA ABUSADORES": RUPTURA DE PERFORMANCE E CRIAÇÃO DE AMBIENTE ONLINE POR AFILIAÇÃO A PARTIR DO CASO DA BANDA PWR BTTM
}

\author{
"Zero tolerance to abusers": Performance rupture and creation of an online \\ ambient affiliation from the PWR BTTM band case
}

\begin{abstract}
"Tolerancia zero para abusadores": Ruptura de performance y creación de ambiente online por afiliación a partir del caso de la banda PWR BTTM
\end{abstract}

Beatriz Medeiros

Doutoranda, Universidade Federal Fluminense

biamedeiros44@gmail.com

Beatriz Polivanov

Professora do Departamento de Estudos Culturais e Mídia e do PPGCOM/UFF, Doutora, Universidade Federal Fluminense beatrizpolivanov@id.uff.br

\section{Resumo}

Relatos íntimos de mulheres que sofreram assédio têm emergido com frequência na internet. $\mathrm{O}$ artigo apresenta o caso de denúncia de abusos sexuais por um dos integrantes da banda PWR BTTM, pertencente à cena de música punk queer nova-iorquina, que aconteceu em 2017. A partir do uso da Linguística Sistêmica Funcional, analisamos postagens no Twitter de pessoas que, antes da denúncia, se entendiam como fãs da banda. Argumentamos que houve uma quebra na "coerência expressiva" da PWR BTTM, que performava, tanto simbólica quanto materialmente, de modo a questionar padrões e comportamentos heteronormativos. Como resultado, gerou-se uma ruptura performática que fez com que muitos dos fãs deixassem de se identificar com a banda, criando um ambiente por afiliação online calcado nas trocas de experiência de ex-fãs desapontados.

Palavras-chave: Ruptura de performance. Ambiente por afiliação online. Banda PWR BTTM.

\begin{abstract}
Intimate narratives of women who suffered sexual and moral harrasment has grown on the internet. This paper presents the denounced case of multiple assaults by one of the PWR BTTM band members, a band from the New York queer-punk music scene, which happened in 2017. With the use of Systemic Functional Linguistic, we analyze posts on Twitter from people that considered themselves fans of the band before the event. We argue that there was a break of "expressive coherence" by PWR BTTM, which performed, symbolic and materially, in ways of questioning heteronormative patterns of behavior. As a result, there was a performance rupture that made a handful of fans no longer identifies themselves with the
\end{abstract}


band, creating an online ambient affiliation based in the exchange of experiences from disappointed ex-fans.

Keywords: Performance rupture. Ambient affiliation. PWR BTTM band.

\section{Resumen}

Los informes íntimos de mujeres que sufrieron acoso moral y sexual han emergido con frecuencia en la internet. Este artículo presenta el caso de denuncia de abusos sexuales por uno de los integrantes de la banda PWR BTTM, perteneciente a la escena de música punk queer neoyorquina, que tuvo lugar en 2017. A partir del uso de la Linguística Sistémica Funcional (LSF), analizamos mensajes en Twitter de personas que, antes de la denuncia, se entendían como fans de la banda. Argumentamos que hubo un rompimiento en la "coherencia expresiva" de PWR BTTM, que performaba, tanto simbólica y materialmente, para cuestionar normas y comportamientos heteronormativos. Como resultado, fue generada una ruptura performática que hice con que muchos de los fans no más se identifiquen con la banda, creando un ambiente por afiliación online calcado en los intercambios de experiencia de ex aficionados decepcionados.

Palabras clave: Ruptura de performance. Ambiente por afiliación online. Banda PWR BTTM.

\section{PREÂMBULO}

Em 2013 o grupo PWR BTTM ${ }^{1}$ foi criado por Liv Bruce (bateria/percussão/vocal) e Ben Hopkins (guitarra/vocal), com influências variadas de bandas como R.E.M. e Nirvana e cantores como James Taylor e Joanna Newson. Em seus videoclipes e shows usavam vestidos e forte maquiagem, sendo considerados uma banda importante não apenas musicalmente, como também socialmente, por desafiarem padrões usuais de gênero masculino / feminino ${ }^{2}$ e serem comprometidos com causas da comunidade LGBTQ ${ }^{3}$.

Em 2015 lançaram seu primeiro álbum e, após excelentes críticas recebidas, produziram o segundo em 2017, com turnê marcada para divulgação. Contudo, poucos dias antes do lançamento, um dos membros da banda, Ben, foi acusado de abuso sexual por uma mulher, levando a um movimento intenso na rede de pessoas que antes se identificavam como fãs da banda, mas que passaram a repudiá-la a partir do ocorrido.

\footnotetext{
${ }^{1} \mathrm{O}$ nome é uma forma abreviada de se escrever a expressão "power bottom”, que é utilizada principalmente por homens em relações sexuais homoafetivas para expressar a preferência pela posição que em português pode ser traduzida como a de "passivo". Fonte: <https://bit.ly/2AtfIi3>. Último acesso em: 25/09/19.

${ }^{2}$ Liv e Ben se identificam como "gender neutral", não se identificando com o gênero masculino nem feminino.

${ }^{3}$ Lésbicas, Gays, Bissexuais, Transgênros e Questionadores / Queer. Também é usual o termo "LGBTQI+" para incluir pessoas intersexuais e outras que não se enquadram nessas categorias.
} 
A partir do caso em questão, neste artigo pretendemos debater sobre como a quebra de confiança entre fã e artista foi capaz de criar o que Zappavigna (2011) chama de "ambiente por afiliação online”, a partir da demonstração de afetações dos anteriormente seguidores e fãs da banda. Apesar de o caso não ter tido um desfecho mais evidente, já que não conseguimos mapear se Ben foi indiciado pelas alegações de violência sexual, o duo perdeu um espaço relevante na cena de música independente queer ${ }^{4}$, não realizando mais nenhum show ou fazendo aparições públicas como banda.

Através da utilização da metodologia da Linguagem Sistêmica Funcional (LSF), no original, Systemic Functional Linguistic (SFL) (ZAPPAVIGNA, 2011, 2014a, 2014b), fizemos um recolhimento de postagens no Twitter - site de rede social (SRS) onde a PWR BTTM mantinha comunicação constante com o seu fandom - utilizando a ferramenta de busca oferecida pela própria plataforma. Percebemos, a partir da coleta de dados, que muitas pessoas seguem comentando sobre as denúncias de abuso sexual, evidenciando a mácula que o acontecimento gerou.

Dessa forma, não é nosso intuito discutir a veracidade ou não das acusações, mas sim que houve uma "ruptura de performance" (FIGUEIREDO, POLIVANOV, 2019; POLIVANOV, CARRERA, 2018) da banda - nesse caso, conectada a uma grave alegação de crimes sexuais $^{5}$ - e que tais rupturas são capazes de fazer não apenas com que o público perca a confiança em relação a uma banda e/ou artista, gerando uma perda de visibilidade ou, até mesmo, o ganho da visibilidade negativa, mas também levantar importantes questionamentos acerca da potência que teriam relatos íntimos de caráter denunciativo mediados pela cultura digital. Defendemos que, nesse caso, as postagens feitas no Twitter, assim como o agenciamento de certos sites que noticiaram e repercutiram as denúncias, foram imprescindíveis. Foi principalmente através do Twitter que a PWR BTTM ganhou visibilidade antes do ocorrido, mas também foi nesse espaço que as denúncias contra Hopkins se espraiaram e fizeram com que a banda cessasse suas atividades (até o momento).

\footnotetext{
${ }^{4}$ A expressão "queer" se refere, nesse contexto, a sujeitos que não são heterossexuais e/ou cisgênero. A partir da década de 1980 o termo, que remete ao significado de algo estranho, passa a ser apropriado de forma positiva por membros de tal comunidade.

5 O termo "sexual assault" se refere a todo e qualquer tipo de contato sexual forçado. Ver: $<$ https://bit.ly/2m2eFzW>. Trata-se de crime grave nos EUA, podendo gerar prisão de 6 meses a 25 anos. Ver: < https://bit.ly/2lXgxdb>. Último acesso em 25/09/19.
} 


\section{ENTENDENDO MELHOR O CASO}

PWR BTTM ganhou notoriedade por causa de sua irreverência, canções que celebram identidades de gênero queer e ações inclusivas da banda, como solicitar banheiros de gênero neutro para os locais onde realizavam suas apresentações. Tiveram como "madrinha" a já mais consolidada The Dresden Dolls, abrindo, inclusive, todos os shows que eles fizeram na turnê de reencontro que percorreu os Estados Unidos em 2016. A banda também possuía uma relevância online significativa, chegando a ter mais de 47 mil seguidores no Twitter, com uma média de 350 novas adesõespor dia, até meados de $2017^{6}$. Sua participação online e a ligação com bandas já consolidadas fizeram com que a PWR BTTM ganhasse ainda mais notoriedade na cena de música alternativa no norte estadunidense, chamando a atenção até mesmo da "grande mídia"7.

No entanto, em 11 maio de 2017, Ben Hopkins foi acusado de "múltiplos abusos sexuais" por uma mulher que frequentava seus shows de forma regular ${ }^{8}$. Essa denúncia fez com que uma série de outras mulheres relatassem situações semelhantes envolvendo o guitarrista, além de trazer à tona outros comportamentos considerados problemáticos por parte de Hopkins - como uma antiga foto sua ao lado de uma suástica desenhada na areia de uma praia ${ }^{9}$.

As acusações, que foram feitas online, rapidamente ganharam a atenção da comunidade de fãs da PWR BTTM, da mídia e também de outros músicos, afetando diretamente a carreira da dupla queer. Na época, Liv Bruce tentou sanar o caso postando uma carta aberta no perfil da própria banda no Twitter ${ }^{10} \mathrm{e}$, uma semana depois, no Facebook ${ }^{11}$. Nas longas mensagens, afirmam que nãohaviam sido contatados em relação ao abuso e que nenhum dos dois estava ciente das situações colocadas pelas vítimas, o que fazia da denúncia um choque para ambos. Na primeira postagem, no Twitter, Liv informa ainda sobre a criação de um e-mail para os "sobreviventes" de abusos sexuais ou pessoas que "trabalham diretamente com sobreviventes que possam discutir as alegações expressadas na mídia social"

\footnotetext{
${ }^{6}$ Ver: <https://bit.ly/2mHalFZ>. Último acesso em 24/09/2019.

${ }^{7}$ Exemplos: <https://nyti.ms/2nhXnPv>, <https://bit.ly/211YL81> e <https://bit.ly/2kY3rvA>. Último acesso em 24/09/2019.

${ }^{8} \mathrm{O}$ primeiro canal midiático a relatar o caso e meio por onde a mulher (que decidiu manter o anonimato) se expressou foi a revista online Jezebel. Vide: 〈https://bit.ly/2nbjl6L〉>. Último acesso em 24/09/2019.

${ }^{9}$ A imagem pode ser vista no mesmo site mencionado na nota anterior.

${ }^{10}$ Ver: <https://bit.ly/210Epfm>. Publicado em 11/05/2017. Último acesso em 24/09/2019.

${ }^{11}$ Ver: <http://bit.ly/2lt9SY2>. Publicado em 18/05/2017. Último acesso em 24/09/2019.
} 
(tradução nossa) $^{12}$. A PWR BTTM não apenas tenta eximir-se da culpa, como também busca perpetuar a construção de confiança que havia construído com a sua fanbase, ao promover um canal aberto de conversa com pessoas que precisariam ser ouvidas.

Essa abertura de canal, contudo, não foi bem vista pelo público que logo criticou a forma como a banda havia se retratado, assim como a suposta mostra de zelo por sobreviventes, quando eles mesmos haviam sido acusados de gaslighting ${ }^{13}$. Esse é o primeiro momento em que se percebe de forma mais clara uma quebra de confiança, engatilhada por uma falta de "coerência expressiva” (PEREIRA DE SÁ, POLIVANOV, 2012) da própria banda, aspecto que iremos discutir melhor ao longo do artigo. Por conta disso, na segunda postagem, no Facebook, o duo relata que irá fechar a conta de e-mail criada.

Porfazer parte de um tipo de grupo no qual as marcas de contraposição a padrões de gênero heteronormativos e defesa da comunidade queer parecem ser uma das bases estruturais, ameaçar a existência de qualquer tipo de liberdade de escolha (principalmente através do uso da violência, como é o caso do abuso sexual) é não apenas uma agressão, mas também uma ruptura de performance em relação à construção identitária da banda e aos laços que vinham sendo construídos com a base de fãs.

Um número expressivo de tweets foi direcionado à banda na época, quando (ex) fãs relataram seus desapontamentos e mesmoraiva com a situação e como a banda se portou após as denúncias. O início do título deste trabalho vem da fala de uma dessas pessoas, Molly Woodstock, que foi publicada como entrevista em matéria de Caitlin Cruz no site Village Voice em 15 de maio de 2017: "Eu acho que é incrível e inspirador o quão rapidamente a comunidade LGBTQ, punk e DIY [do it yourself] se mobilizou para responsabilizá-los [os integrantes da banda] e mostrar uma política de tolerância zero para abusadores" (CRUZ, 2017, online, tradução nossa).

Reforçamos que não possuímos a pretensão de, nem nos cabe, julgar o caso e tampouco a veracidade da denúncia. Ele, no entanto, afetou de tal forma a imagem da dupla que, até este momento (setembro de 2019), não retornaram às suas atividades artísticas.

A PWR BTTM teve também uma queda significativa de seguidores na época da denúncia:mais de 47 mil em maio de 2017, para cerca de 40 mil no mês seguinte e, no final

\footnotetext{
12 Original: "or someone working directly with a survivor can discuss the allegations being expressed on social media".

${ }^{13}$ Forma de manipulação psicológica que tem como objetivo fazer com que a vítima duvide de sua capacidade mental, com relação à lembrança e percepção de fatos que tenham ocorrido. Vide: 〈http://bit.ly/2ltqLlq>. Último acesso em 25/09/2019.
} 
do mesmo ano, chegando a 35 mil seguidores. Atualmente, a banda está com 28.108 seguidores, mas perde uma média de sete por $\operatorname{dia}^{14}$. As últimas postagens feitas em SRS datam de 11 de maio de 2017 (Twitter) e 18 de maio de 2017 (Facebook), ambas fazendo referência à denúncia da (ex)fã. $\mathrm{O}$ duo parou suas atividades, teve sua turnê e contrato com gravadora cancelados e suas músicas foram retiradas de serviços de streaming $^{15}$.

Tendo tal cenário em vista, nos apoiamos na Linguística Sistêmica Funcional (LSF) para analisar os discursos que circularam no Twitter sobre a banda a partir de tal ruptura de performance.

\section{A LINGUÍSTICA SISTÊMICA FUNCIONAL COMO METODOLOGIA}

A Linguística Sistêmica Funcional (LSF) - como foi livremente traduzido por nós - é uma metodologia que surgiu para dar conta das usabilidades e linguagens empregadas em interações que acontecem em sites de redes sociais (ZAPPAVIGNA, 2011). Ela é, portanto, pertinente quando o objetivo de pesquisa desse relaciona com a análise de conteúdos online, que contam com características específicas quanto, por exemplo, à busca de termos e o contexto das trocas conversacionais.

A LSF começou a ser empregada na área do estudo de linguagem, mais especificadamente na área de gramática:

Como uma teoria gramatical, [a Gramática Sistêmica Funcional] é um recurso de envolvimento da gramática de toda linguagem humana, e oferece uma aproximação de análise da gramática de uma linguagem nos termos em como a linguagem é utilizada ${ }^{16}$. (BO WANG, 2014, p. 54)

Essa metodologia, criada nos anos 1960 por Halliday (1961 apud WANG, 2014), ganhou um espaço significativo na área de linguística e foi adotada também por outros segmentos, como a área de estudos midiáticos (ZAPPAVIGNA, 2011, 2014a, 2014b, 2016).

Tendo em vista que a linguagem online varia de acordo com o seu contexto, plataforma utilizada e grupo social que a emprega (AMARAL, 2011; RECUERO, 2009), é possível aplicar a LSF em distintos sites de redes sociais, atentando para suas especificidades

\footnotetext{
${ }^{14}$ Última checagem feita em 28/09/2019.

${ }^{15}$ Forma de distribuição digital de conteúdos multimidáticos. A plataforma Spotify é uma das mais utilizadas. As informações sobre o posicionamento da banda e repercussões geradas pelas denúncias podem ser encontradas em: <http://bit.ly/2mA3uhG>. Último acesso em: 28/09/2019.

${ }^{16}$ Original: "As a theory of grammar, it is a resource of engaging with the grammar of all human language, and it offers an approach of viewing the grammar of a language in terms of how language is used".
} 
de estrutura e uso. Como Zappavigna (2011, p. 790, tradução nossa) deixa claro, "é uma teoria semiótica social que investiga o discurso em um contexto" ${ }^{17}$. Isso quer dizer que, ao escolhermos a LSF como uma metodologia de pesquisa, devemos levar em consideração o espaço onde as pessoas se encontram como um potencial influenciador direto nos discursos que são elaborados.

Essa metodologia é exclusivamente utilizada em comunicações online, pois ela será dependente de programas e mecanismos de busca que possam localizar um conteúdo específico em plataformas digitais, a partir dos "rastros" que são criados dentro desses ambientes à medida em que o/a usuário/a as utiliza. Para fazer a coleta dos discursos relacionados ao caso fizemos buscas pelo próprio nome da banda.

A plataforma de busca do Twitter oferece cinco opções de filtro mais gerais de busca e duas mais específicas relacionada à categoria "Pessoas" (em que se opta por encontrar tweets de "Qualquer pessoa" ou "Pessoas que você segue") e "Localização" (em que se opta por tweets de pessoas "Em qualquer lugar" ou "Perto de você"). Os filtros mais gerais são: "Principais" (ou seja, os principais tweets ${ }^{18}$ com o termo procurado), "Mais recentes" (mostra tweets em ordem cronológica de postagem), "Pessoas" (direciona para páginas que possuem o termo pesquisado no nome de usuário ${ }^{19}$, ou no nome de identificação), "Fotos" (mostra apenas tweets com fotografias) e "Vídeos" (mostra apenas tweets com vídeos, ou links de direcionamento para plataformas de vídeo, como YouTube). Dessas opções de filtro, escolhemos nos ater ao marcador cronológico, "Mais recentes" de "Qualquer pessoa" "Em qualquer lugar".

A escolha da aplicação da LSF no Twitter é importante, pois ele não apenas era o espaço de maior atividade de interação da PWR BTTM com seu público, como também é um ambiente capaz de mediar a aproximação de pessoas que partilham de determinado interesse em comum e deixa tais afiliações rastreáveis. Tal ideia nos remete aos "ambientes por afiliação", que estão vinculados a "laços sociais" que "são ajustados com o objetivo de realizar a comunhão de uma audiência de massa online" ${ }^{20}$ (ZAPPAVIGNA, 2014a, p. 210, tradução nossa).

\footnotetext{
${ }^{17}$ Original: "SFL is social semiotic theory that investigates discourse in context".

${ }^{18} \mathrm{O}$ Twitter utiliza como critério para a definição de tweets como principais a temporalidade e o número de engajamento que as postagens estimularam. Tweet é sinônimo de uma publicação feita no Twitter.

${ }^{19}$ Identificado pelo arroba (@).

${ }^{20}$ Original: "social bonds are configured in order to commune with a mass online audience".
} 
Aventamos como hipótese, ao observar as interações realizadas entre a banda e seus seguidores e também dentre este último grupo - através do perfil @PWRBTTMBAND, quanto de perfis pessoais - que sua quebra de coerência expressiva teria unido ex seguidores da banda, criando um ambiente por afiliação online calcado no compartilhamento de sentimentos, opiniões e impressões sobre as denúncias, vinculadas à ideia de decepção com o que se entendia que era o posicionamento do duo. Ou seja, o relato-denúncia inicial, corroborado por outros relatos e a própria forma de a banda se colocar frente ao ocorrido, teriam gerado uma ruptura de performance da mesma, que trouxe como consequência não apenas o fim do grupo, mas também essa união de sujeitos que antes o seguiam e agora passam a ser entendidos através da noção de "ex-fãs" (PILZ et al., 2018).

\section{DENÚNCIAS ÍNTIMAS NA WEB E RUPTURAS DE PERFORMANCE}

Entendemos que o caso de denúncia aqui analisado faz parte de um cenário mais amplo de narrativas autobiográficas que têm surgido recentemente na cultura digital que visam desconstruir idealizações de certos tipos sociais, como de musicistas que podem ser entendidos como "alternativos", como o trabalho de Pilz et al. (2018), ao trazer o caso da banda brasileira Apanhador Só, que teve um dos seus integrantes acusado por sua excompanheira de abusos físicos e psicológicos.

Tais relatos pessoais, tanto os trazidos no artigo de Pilz et al. (2018), quanto neste trabalho, parecem ter algumas características em comum, quais sejam:

- são de autoria de pessoas "comuns", isto é, não se trata de celebridades, já com alto capital de visibilidade;

- possuem um caráter de denúncia, seja contra um sujeito em específico ou uma construção de certos grupos sociais - não buscam somente "colocar para fora" certo sentimento ou testemunho, mas também que haja algum tipo de repercussão / consequência sobre o que se relata;

- são escritos em primeira pessoa, gerando um lugar de fala de autenticidade vinculado a uma ideia de "aconteceu comigo; é real";

- em geral são publicados através de seus próprios perfis pessoais em SRS como Facebook ou Twitter de forma não anônima, reforçando o valor de autenticidade; podendo ou não estar vinculados a campanhas coletivas de denúncia como a \#meuprimeiroassédio (SILVEIRA, 2018) e podem eventualmente se apropriar de 
hashtags para ganhar mais visibilidade;

- geram fissuras ou rupturas nas imagens que se tinha seja do sujeito ou grupo social em questão, potencializando, no caso de artistas / musicistas, a formação de grupos de "ex-fãs".

Assim, entendemos que casos como o da PWR BTTW estão inseridos em um contexto contemporâneo que dialoga com ou talvez até mesmo se inspire em campanhas ciberfeministas, como as analisadas por Júlia Silveira em sua tese de doutorado. A autora defende que

narrar e compartilhar episódios de abuso ou violências sofridas como forma de coletivizar a experiência e lhe atribuir um sentido político e uma contribuição coletiva pode ressignificar essas experiências traumáticas. Ao escrever e publicar sobre o trauma vivido, a internauta tem a possibilidade de deslocar-se do lugar original de vítima - no âmbito da vergonha, do constrangimento e da culpabilização - e assumir um caráter ativo e ativista, cuja contribuição confere legitimidade para si, enquanto participante de um movimento contestatório (SILVEIRA, 2018, p. 150).

Ainda que o caso aqui analisado se inicie a partir de uma manifestação de uma mulher em específico e não faça necessariamente uma convocação a uma atuação coletiva - e nem deva ser considerado como uma expressão de "ativismo" - certamente dialoga com um cenário fértil de expressões íntimas e individuais que têm vindo à tona denunciando comportamentos inaceitáveis que talvez antes não fossem questionados publicamente.

O fato de tais denúncias serem feitas através de ambientes online é um ponto relevante a ser destacado, uma vez que remete a três valores específicos de tais espaços: a visibilidade, o alcance que tais mensagens podem obter e a possibilidade de serem deixados "rastros digitais" (BRUNO, 2012), possivelmente indeléveis e recuperáveis, causando afetações mesmo posteriores para as imagens dos envolvidos. As narrativas de denúncias tendem, assim, a se espraiar rapidamente pela web e nelas permanecer, alcançando inclusive públicos que antes poderiam nem sequer conhecer os sujeitos denunciados.

Contudo, mais do que uma questão quantitativa que envolve número de visualizações e compartilhamentos de tais mensagens, acreditamos que está em jogo também uma dimensão mais qualitativa, por assim dizer, sobre a repercussão que cada caso possa ganhar.

No caso de bandas / artistas, um mesmo tipo de denúncia - de violência sexual contra uma mulher por um dos seus integrantes, por exemplo - pode gerar maior ou menor repercussão, dependendo do quanto se afasta da imagem que se tem dos mesmos. É nesse sentido que evocamos a noção de "coerência expressiva" (discutida por Pereira de Sá, Polivanov, 
2012), que diz respeito à tentativa que temos, enquanto seres sociais, de mantermos as narrativas autobiográficas de nós mesmos minimamente coerentes, a partir de um processo de autorreflexividade que marcaria a própria modernidade (GIDDENS, 2002). Trata-se, contudo, de um processo sempre sujeito a rupturas. Conforme explica Goffman (2009):

Dada a fragilidade e a necessária coerência expressiva da realidade que é dramatizada por uma representação, há geralmente fatos que, casos expostos à atenção durante a representação, poderão desacreditar, romper ou tornar inútil a impressão que ela estimula. Diz-se que estes fatos fornecem "informação destrutiva" (GOFFMAN, 2009, p. 132).

O que estamos chamamos aqui, portanto, de ruptura de performance, em consonância com trabalhos já mencionados, diz respeito justamente a esses fatos que são expostos sobre os atores sociais, trazendo-lhes uma "informação destrutiva" que lhes quebra sua intencionalidade de expressão.

No caso da PWR BTTW há indícios de uma forte ruptura quanto à imagem que se tinha da banda, que se colocava num lugar de problematizar questões de gênero a partir de óticas não normativas e um de seus integrantes teria precisamente reforçado um comportamento heteronormativo inaceitável de agressão sexual contra uma mulher. Desse modo, a percepção de uma ideia de desilusão, de "incoerência expressiva" que gera uma ruptura de performance ${ }^{21}$, parece-nos que fica clara, como veremos na seção seguinte a partir da discussão dos dados.

\section{DISCUSSÃO DE DADOS}

Originalmente, as mensagens recolhidas do Twitter para este artigo datam de aproximadamente um ano depois do evento envolvendo a PWR BTTM. O primeiro recolhimento foi feito do dia 02 de fevereiro a 29 de março de 2018. Observando a necessidade de atualização do material empírico, fizemos uma nova coleta no mês de setembro de 2019, do dia 01 ao dia 20. Esta segunda teve os mesmos princípios da primeira: realizamos o recolhimento de tweets de forma cronológica, selecionando a barra de "Mais recentes" do Twitter, e utilizamos o termo "PWR BTTM" na ferramenta de busca para poder fazer a seleção de dados. Como o termo também é uma expressão da cena queer falante de

\footnotetext{
${ }^{21}$ Conforme apontam Soares et al. (2018, p. 64): “é importante atentar para quando certas intencionalidades performáticas não se cumprem, sendo rompidas (...) levar em consideração também as falhas, os desencaixes que por ora ocorrem (...), gerando afetações no público e na autoimagem que se deseja construir".
} 
língua inglesa (com o sentido de "passivo"), descartamos os tweets que usavam o termo nessa acepção, que não faziam referência à banda. Também encontramos um número de tweets com indicações de músicas da banda, que também foram desconsiderados. Dessa forma, deixamos em evidência apenas as mensagens que referenciavam o grupo e o acontecimento, bem como os sentimentos que elas tinham conforme o desenrolar do evento, totalizando, ao final, 55 tweets.

\subsection{RASTROS DURÁVEIS DAS AFETAÇÕES NEGATIVAS}

A forma como as pessoas ainda comentam, espontaneamente, sobre a PWR BTTM ${ }^{22}$ e demonstram suas opiniões dá a entender que, por mais que a mesma tenha encerrado suas atividades - de forma não oficial, já que não houve uma declaração pública de término - ela ainda é um assunto constante na vida dos sujeitos que a seguiam, dentro da comunidade LGBTQ. Esse tipo de mensagem pode ser lido como uma forma de compartilhamento de sentimentos, o que possibilita a criação de um ambiente por afiliação. Nas palavras de Zappavigna (2014a, p. 212, tradução nossa), "compartilhar sentimento é central tanto para a promoção de interação social quanto para comunicar os valores que mostram quem somos"23. Dessa forma, percebemos a criação de espaços de afinidade a partir de mensagens que conotam sentimentos parecidos, fazendo com que as pessoas possam se aproximar umas das outras pela empatia. As imagens a seguir trazem algumas das narrativas que corroboram a criação de espaços de afinidade através do compartilhamento de emoções.

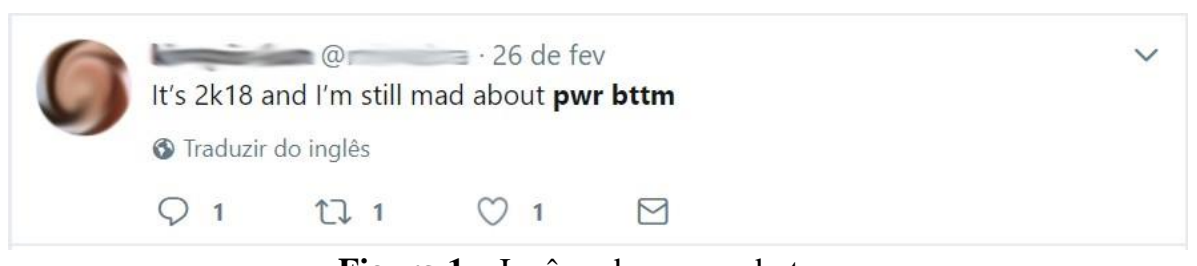

Figura 1 - Incômodo apesar do tempo

Fonte: Twitter/print screen

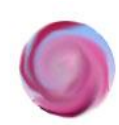

@)

- 6 de set

real shame PWRBTTM are a sexual abuser \& the defender of such

every time i get one of their songs stuck in my head it bums me out

\footnotetext{
${ }^{22}$ Alteramos as imagens dos perfis e nomes dos usuários para torná-los anônimos, ainda que suas publicações sejam públicas no Twitter.

${ }^{23}$ Original: "Sharing feeling is central to both fostering social interaction and communicating the values that signify who we are".
} 
Figura 2 - Chateação e mácula da banda

Fonte: Twitter/print screen

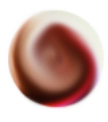

24 de fev

I'm still fucking pissed that PWR BTTM ended up being scumbags

(1) Traduzir do inglês

$1 \quad O_{1} \quad \square$
Figura 3- Raiva e xingamentos
Fonte: Twitter/print screen

Nas três figuras 1, 2 e 3, demonstradas acima, podemos observar mensagens que apresentam o mesmo tom e objetivo: demonstrar que ainda existe a sensação de frustração em relação à PWR BTTM. Trata-se de relatos pessoais de sensações ligadas a afetações negativas pelas interjeições: "irritada", "incômodo" e "raiva". Essas expressões são ilustrativas de sensações e o tom de informalidade e até sarcasmo fornecem uma camada a mais nessa conotação, aproximando essas pessoas, ainda que elas não estejam falando entre si ou mesmo realizando trocas.

A figura 1, que é traduzida como: "É 2018 e eu ainda estou irritada com a pwr bttm", deixa a temporalidade cronológica clara. A denúncia contra Ben Hopkins se deu em março de 2017, ainda assim, em fevereiro de 2018, um ano depois, a ex-fã não consegue deixar de lado o ocorrido. O uso da palavra still dá uma ideia de continuidade sem prazo de fim.

A figura 2, de 2019, pode ser traduzida como: "É realmente uma pena que a PWRBTTM [sic] seja [formada] por um abusador e um defensor dele. me chateia sempre que eu fico com uma das músicas deles presa na minha cabeça". Observamos que não apenas a ex-fã não consegue se desvencilhar da sensação que ela teve no momento em que a banda foi denunciada, como isso produz um efeito direto na memória afetiva da mesma, gerando uma mácula na relação fã-artista, nesse caso. Esta ex-fã não desassocia a denúncia, e sua crença na mesma, de 2017 contra a PWR BTTM das canções da banda e provavelmente nem mesmo as escuta mais - tendo em vista que a lembrança dessas a deixa incomodada.

A figura 3 pode ser traduzida do seguinte modo: "Eu ainda estou irritada pra caralho que a PWR BTTM acabou sendo sacana”. Nessa, podemos observar a irritabilidade não apenas pela auto-declaração, mas também pelo uso de palavras ofensivas, tanto para conotar aumentativo (o uso de fucking não tem tradução literal), quanto para ofender a própria PWR BTTM (scumbag é um termo que em inglês é uma ofensa severa).

Esses três tweets, portanto, são exemplos que ilustram a forma como a PWR BTTM ainda é vista pelo público. Dessa forma, é possível dizer que nem o relato dos próprios integrantes, ou a retratação que eles postaram tanto no Facebook quanto no Twitter foram 
capazes de modificar a percepção que alguns (ex) fãs obtiveram deles na época. Muitos, até hoje, mostram problemas para superar a frustração que sentiram quando a dupla foi denunciada.

Assim, propomos entender tais manifestações de ex-fãs enquanto "rastros duráveis", que esticam a temporalidade de duração do evento para além do momento em que as denúncias vieram à tona. Conforme argumentam Vaz e Santos (2017), traumas, de uma forma mais ampla e inseridos no contexto midiático contemporâneo, costumam ter essa marca temporal: não se findam, são construídos de modo a não passarem, a serem rememorados e mesmo "contagiarem" outros a falarem sobre suas experiências também. Não estamos aqui lidando com os traumas em si de quem fez as denúncias à banda, mas julgamos essa percepção de uma temporalidade estendida do fenômeno relevante, uma vez que demonstra que os relatos pessoais em SRS podem gerar repercussões e mesmo mudanças mais duradouras no cenário midiático e social contemporâneo. Sem incorrer em uma visão otimista sobre a potência desses ambientes - ainda mais no contexto pós-eleições no Brasil - destacase aqui que uma conjuntura calcada em movimentos feministas e queer e nos relatos de pessoas comuns na rede têm a possibilidade de trazer falas de sujeitos que talvez em um contexto anterior necessitassem de um endosso (nem sempre conseguido) de meios de comunicação massivos para serem ouvidas, e agora ainda se espraiam com mais rapidez e alcance.

\subsection{QUEBRA DE IDENTIFICAÇÃO}

Outros relatos possuem um tom de pessoalidade ainda maior em relação aos comentaristas e à banda. Existe, nesses casos, uma expressão de relação de identificação profunda, que é quebrada a partir do momento da acusação direcionada à banda de uma forma geral. Essa percepção de familiaridade que o público possui (ou constrói) com uma banda não é incomum (MONTEIRO, 2011) e, no caso da PWR BTTM, acontece justamente por causa da identificação que o próprio público apresenta ao fazer parte de uma cultura e/ou cena queer. A criação de um senso de comunidade entre um performer queer e o público que observa a performance, no entanto, não é um mérito único e exclusivo da PWR BTTM, sendo realizado, por exemplo, em peças teatrais por atores que brincavam com a ideia de "real" e "falso", "revelando comprometimento ontológico e epistemológico com o público homossexual 
queer"24 (DANIEL, 2013, p. 14, tradução nossa). Esse tipo de processo de criação de comunidade possui uma relevância, principalmente no que se refere a um grupo social que apresenta diferentes tipos de ameaças tanto com relação ao apagamento histórico, social e cultural, quanto em relação a violências físicas e simbólicas sofridas (HALBERSTAM, 2003).

Essa sensação de pertencimento pode ser observada na figura 4, quando o ex-fã assume que sua decepção com relação ao conflito envolvendo a PWR BTTM se dá porque a banda "era exatamente o meu som e nicho". Novamente o uso de palavras depreciativas aparece nesse tweet (piece of shit, ou, traduzindo livremente, pedaço de merda) com o objetivo de depreciar Ben Hopkins - agente principal causador da quebra de confiança entre banda e fã.

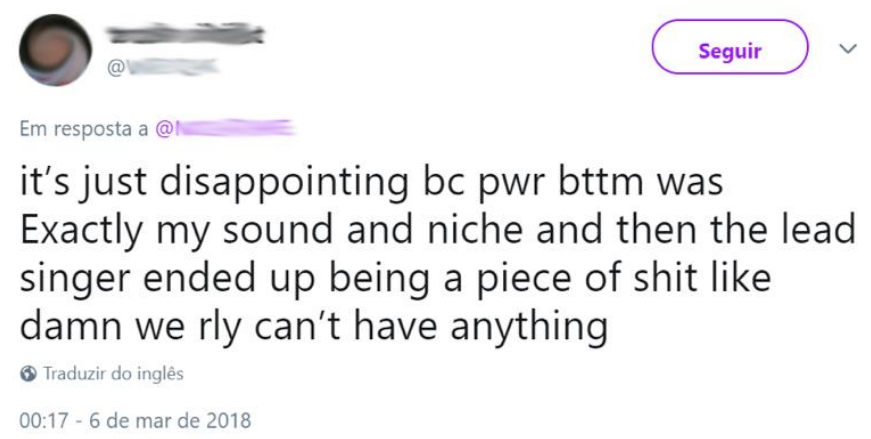

Figura 4 - Declaração de desapontamento Fonte: Twitter/print screen

Seguindo a mesma lógica da figura 4 , na figura 5 conseguimos observar a quebra de confiança, novamente criando um ambiente de filiação - ainda que as postagens não tenham menções diretas entre si.

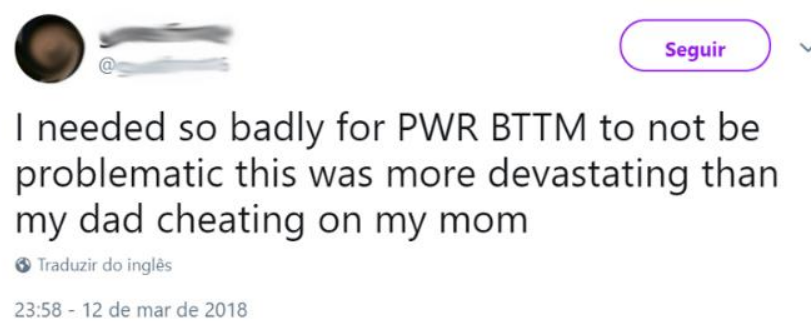

Figura 5 - Quebra da expectativa atrala à quebra de confiança Fonte: Twitter/print screen

Nela, há a expressão de uma necessidade de que a PWR BTTM não se mostrasse como algo "problemático". Todo o conflito foi para a comentarista algo pior do que um

${ }^{24}$ Original: "disclosing ontological and epistemological commitment to queer homosexual public". 
evento familiar traumático - como é relatado. Percebemos nesse momento um lamento pelo que aconteceu, pois há a perda da sensação de comunidade. Ainda que não haja uma ligação direta de participação de nicho com relação ao comentarista da figura 5 em específico, é possível inferir que há uma sensação de identificação por parte dele em relação à banda. $\mathrm{O}$ uso da palavra "necessidade" soa quase como uma declaração desesperada por causa da quebra da coerência expressiva da banda que acabou ocorrendo. Essa necessidade também pode ser entendida como algo presente em comunidades queer de se mostrarem de alguma forma diferenciadas de núcleos familiares normativos, destacando-se até mesmo de comunidades gays e lésbicas. Nas palavras de Halberstam (2003, p. 314-315, tradução nossa), enquanto existe a construção política e normativa que permeia as pautas da construção de uma “comunidade gay e lésbica" 25 , "subculturas queer preservam a crítica da heteronormatividade que sempre esteve implícita na vida queer" ${ }^{26}$. Ao ser denunciado por práticas de violência comuns em meios heteronormativos e falocêntricos, portanto, Hopkins ameaça quebrar a lógica de construção de comunidade queer engendrada ao redor da PWR BTTM, sendo ela uma representante dos valores de uma comunidade maior. Ao fazê-lo, teria também rompido com uma ideia de "espaço seguro" ("safe space"), cara a comunidades LGBTQ 27 . A comunidade existente por causa da banda, no entanto, continua persistindo, no que é possível observar a emergência dos ambientes de afiliação - ainda que com o propósito da demonstração de uma decepção por causa de uma ruptura de performance.

\subsection{CANCELAMENTO DA BANDA}

Uma das categorias emergentes na segunda coleta realizada em 2019 foi a percepção de cancelamento artístico da PWR BTTM. Este tipo de prática, conhecida como "cultura do cancelamento" (cancel culture, em inglês), começou a ser realizada por alguns grupos em espaços on a partir da hashtag \#cancelled contra pessoas - e também eventos e mesmo produtos artísticos, como filmes - que se vincularam a atitudes não aceitáveis ou problemáticas, ligadas, por exemplo, ao racismo e homofobia ${ }^{28}$.

\footnotetext{
25 Original: "gay and lesbian community".

${ }^{26}$ Original: "queer subcultures preserve the critique of heteronormativity that was always implicit in queer life."

27 A ideia de "espaços seguros" remete à proteção e acolhimento que pessoas LGBT deveriam sentir uma vez estando neles. Fora do Brasil é comum que alguns lugares sejam identificados inclusive com placas coloridas identificadas como "safe zone" em ambientes como casas de shows. A fala de Paige Jordan à matéria de Cruz (2017), traz essa noção: "To know that they weren't who they pretended to be, and for all their pretense of creating a safe space, they were actually the unsafe space - it's so shitty".

28 Vide: <http://bit.ly/2lv71N3>. Último acesso em 25/09/2019.
} 
Similar a um boicote, esse tipo de ação teria iniciado em 2015 a partir do movimento Black Twitter, e foi ganhando força dentre outros grupos, principalmente aqueles relacionados à cultura de comunidades marginalizadas - mais notavelmente feministas e LGBTQ. As imagens abaixo trazem tweets nos quais os usuários utilizam efetivamente o termo "cancelar" para se referir à banda PWR BTTM:

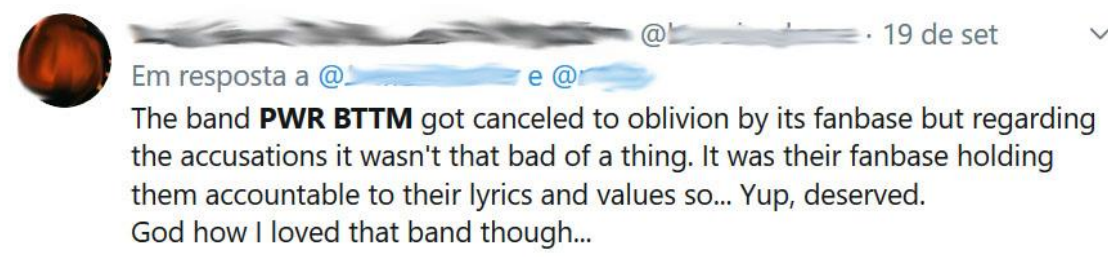

Figura 6 - Cancelamento como algo positivo, ainda que dolorido Fonte: Twitter/print screen

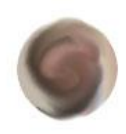

De@.

hey, remember PWR BTTM? I didn't until just now. One of the cleanest cancellations of all time

Q 1 ○】 010 个

Figura 7 - Cancelamento mais "efetivo"

Fonte: Twitter/print screen

Esse tipo de ação contra a PWR BTTM aconteceu por conta da ruptura de performance da banda, conforme argumentamos. Na figura 6, a mensagem deixa isso claro: “A banda PWR BTTM foi cancelada até o esquecimento por sua base de fãs, mas, apesar das acusações, não era tão ruim. Foi a sua base de fãs que os responsabilizou por causa de suas composições e valores então... Sim, merecido. Mas, deus, eu amava aquela banda...”. Existe na narrativa a percepção de que o cancelamento se deu justamente porque a banda foi de encontro com os valores que demonstrava em sua performance. Para quem fez o tweet, o cancelamento foi merecido, ainda que ela tenha gostado muito da banda até então, demarcando sua passagem de fã para ex-fã a partir da ruptura de performance da mesma.

A figura 7, por sua vez, pode ser traduzida por: “ei, se lembra da PWR BTTM? Eu não [lembrava] até ainda a pouco. Um dos cancelamentos mais eficazes de todos os tempos". Ela deixa em evidência um dos objetivos da cultura de cancelamento: o apagamento da memória pública de artistas, bandas ou celebridades "incoerentes". Apesar disso, a PWR BTTM não foi efetivamente esquecida, havendo até hoje comentários como os acima De outra maneira, ela passou a ser associada com denuncias sérias que foram feitas contra a dupla queer, levando ao 
seu fim - ao menos até este momento - e uma mudança talvez irreversível na imagem da mesma - algo que talvez seja pior do que o simples esquecimento.

\section{CONSIDERAÇÕES FINAIS}

O caso de denúncia sexual dirigido a um dos integrantes da dupla queer PWR BTTM nos chamou a atenção por uma série de razões. Em primeiro lugar ele faz parte de um cenário mais amplo no qual relatos íntimos (principalmente de mulheres) têm emergido nos sites de redes sociais, trazendo à tona graves acusações contra artistas em alguns casos. Mais especificamente o caso gerou, conforme argumentamos, uma ruptura com as performances que a banda realizava em termos de questionamento de comportamentos tidos como heteronormativos.

Tal ruptura acabou levando não apenas ao fim (ao menos por ora) da banda e a uma diminuição significativa nos números de seguidores da banda, mas principalmente à construção do que Zappavigna chama de "ambientes por afiliação", isto é, comunidades que se unem em espaços online a partir de interesses e perspectivas em comum. No caso aqui analisado, tal afiliação se deu a partir de um sentimento comum de decepção e mesmo raiva perante a banda, a partir da sua "incoerência expressiva". Assim, propomos que tais sujeitos possam ser entendidos enquanto ex-fãs da mesma.

Através de uma abordagem da Linguística Sistêmica Funcional (LSF), analisamos as expressões narrativas de alguns desses que podemos chamar de ex-fãs e apontamos três momentos que foram mapeados a partir de suas manifestações pessoais nos SRS: 1) o surgimento das afetações negativas que o caso gerou devido a uma falta de coerência expressiva da banda; 2) uma quebra de identificação dos sujeitos com a banda, a partir de sua ruptura performática; e 3) o cancelamento da banda.

Mais de dois anos após o acontecimento, marcas profundas foram deixadas no público conhecedor da banda por conta da denúncia e da forma como a PWR BTTM tentou realizar um "gerenciamento de crise" (PILZ et al., 2018) com relação ao conflito e tentar se eximir, até certo ponto, da culpa. Ainda, apontamos como o caso segue gerando manifestações de repúdio (mesmo que por vezes vinculado também a um sentimento de saudosismo), indicando talvez um caráter de irreversibilidade da ruptura. Destacamos, assim, a potência dos relatos íntimos na internet como modos de lidarmos com problemáticas sociais relevantes, como a violência contra as mulheres, por um lado, e por outro atentamos para a desconstrução de uma 
identificação com os membros da banda que pode acabar gerando um sentimento de união a partir da configuração deste novo lugar: o dos ex-fãs, sobre o qual pretendemos discutir de modo mais aprofundado em trabalhos futuros.

\section{REFERÊNCIAS}

AMARAL, Adriana. Redes sociais, linguagem e disputas simbólicas. ComCiência, Campinas: Unicamp, n. 131, 2011.

BRUNO, Fernanda. Rastros digitais sob a perspectiva da teoria ator-rede. Revista FAMECOS, Porto Alegre: PUC-RS, v. 19, n. 3, p. 681-704, set./dez., 2012.

CRUZ, Caitlin. "How PWR BTTM's Fans Are Dealing With The Troubling Allegations Against The Band", The Village Voice, 15 de maio de 2017. Acervo online: < https://bit.ly/2nCcwLr>. Acesso em 25 set. 2019.

DANIEL, Drew. “Why Be Something That You're Not?": Punk Performance and Epistemology of Queer Minstrelsy. Social Text 116, Durham: Duke University Press, v. 31, n. 3, p. 13-34, set., 2013.

FIGUEIREDO, Ana Luiza; POLIVANOV, Beatriz. "Ninguém fala do lado assustador de ser mãe": testemunho no Facebook enquanto ruptura de performances idealizadas da maternidade. Revista Fronteiras - Estudos Midiáticos, São Leopoldo: Unisinos, v. 21, n. 1, p. 41-51, jan-abr 2019.

GIDDENS, Anthony. Modernidade e identidade. Rio de Janeiro: Jorge Zahar Editor, 2002.

GOFFMAN, Erving. A representação do eu na vida cotidiana. 16 edição. Petrópolis: Vozes, 2009.

HALBERSTAM, Judith. What's That Smell?: Queer Temporalities And Subcultural Lives.

International Journal of Cultural Studies, California: SAGE journals, v. 6, n. 313, p. 313-333, set., 2003.

MONTEIRO, Camila. Fã-mília \#happyrock: "recomeço" em cores. In: SIMPÓSIO EM TECNOLOGIAS DIGITAIS E SOCIABILIDADE, 2011, Salvador. Acervo online. $<$ http://gitsufba.net/simposio/wpcontent/uploads/2011/09/Familia_happyrock_recomeco_em_cores_Camila_Monteiro.pdf $>$. Acesso em 15 mai. 2018.

PEREIRA DE SÁ, Simone; POLIVANOV, Beatriz. Auto-reflexividade, coerência expressiva e performance como categorias para análise os sites de redes sociais. Contemporânea - Comunicação e Cultura, v. 10, n. 3, p. 574-596, 2012.

PILZ, Jonas; POLIVANOV, Beatriz; HENN, Ronaldo; MEDEIROS, Beatriz. Apanhador Não Tão Só: um testemunho, uma banda e as afetações de um ciberacontecimento. In: ENCONTRO ANUAL DA COMPÓS, 27º , 2018, Belo Horizonte. Anais... Compós: Belo Horizonte, 2018.

POLIVANOV, Beatriz; CARRERA, Fernanda. Rupturas performáticas em sites de redes sociais: um olhar sobre fissuras no processo de apresentação de si a partir de e para além de Goffman. Revista Intexto, Porto Alegre: UFRGS, n. 44, p. 74-98, jan-abr 2019. 
RECUERO, Raquel. Diga-me com quem falas e dir-te-ei quem és: a conversação mediada pelo computador e as redes sociais na internet. Revista FAMECOS, Porto Alegre: PUC-RS, v. 16, n. 38, p. 118-128, abr., 2009.

SILVEIRA, Julia. Minha rede, minhas regras: Hashtags, mobilização de mulheres e publicação de narrativas íntimas na internet. Tese apresentada ao Programa de Pós-Graduação em Comunicação da Universidade Federal Fluminense, como requisito parcial para obtenção do Grau de Doutora, 2018.

SOARES, Thiago; AMARAL, Adriana; POLIVANOV, Beatriz. Disputas sobre performance nos estudos de Comunicação: desafios teóricos, derivas metodológicas. Revista Intercom - RBCC, São Paulo: Intercom v. 41, n. 1, p. 63-79, jan./abr., 2018.

VAZ, Paulo; SANTOS, Amanda. Trauma, identidade e testemunho: Deslocamentos conceituais e a construção da subjetividade contemporânea. São Paulo: Anais do XXVI Encontro Anual da Compós, 2017. Disponível em:

http://www.compos.org.br/data/arquivos_2017/trabalhos_arquivo_GZ1LQGDV80P5W8N8T1M0_26 _5700_20_02_2017_21_05_05.pdf. Acesso em: 15 mai. 2018.

WANG, Bo. Theme in Translation: A Systemic Functional Linguistic Perspective. International Journal of Comparative Literature \& Translation Studies, Doncaster: Australian International Academic Center, v. 2, n. 4, p. 54-63, out., 2014.

ZAPPAVIGNA, Michele. Ambient affiliation: A linguistic perspective on Twitter. New Media \& Society, California: SAGE journals, v. 13, n. 5, p. 788-806, mai., 2011.

ZAPPAVIGNA, Michele. Enacting Microblogging through Ambient Affiliation. Discourse \& Communication, California: SAGE journals, v. 8, n. 2, p. 209-228, mai., 2014a.

ZAPPAVIGNA, Michele. Enjoy your snags Australia ... oh and the voting thing too \#ausvotes \#auspol: Iconisation and affiliation in electoral microblogging. Global Media Journal, Heathrow: Global Media Journal, vol. 8, n. 2, p. 1-16, nov., 2014b.

Original recebido em: 04 de dezembro de 2018

Aceito para publicação em: 29 de agosto de 2019

Beatriz Medeiros

Doutoranda do PPGCOM da UFF, bolsista CAPES. Mestre em Comunicação pela mesma instituição. Bacharela em Estudos de Mídia. Integrante dos grupos de pesquisa MiDICom e

MUSILAB.

Beatriz Polivanov

Professora do Departamento de Estudos Culturais e Mídia da Universidade Federal Fluminense (UFF) e docente permanente do PPGCOM na mesma instituição. Professora visitante do Departamento de Art History and Communication Studies da McGill University. Doutora e mestre pelo PPGCOM/UFF. Líder do grupo de pesquisa MiDICom. 


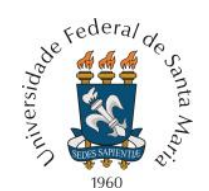

PROGRAMA DE PÓS-GRADUAÇÃO EM COMUNICAÇÃO DA UNIVERSIDADE FEDERAL DE SANTA MARIA

\section{()요}

Esta obra está licenciada com uma Licença

Creative Commons Atribuição-NãoComercial-CompartilhaIgual 4.0 Internacional 